Article

\title{
Structure and Doping Optimization of IDT-Based Copolymers for Thermoelectrics
}

\author{
Tongchao Liu ${ }^{1,2}$, Dexun Xie ${ }^{1, *}$, Jinjia $\mathrm{Xu}^{3}$ and Chengjun Pan ${ }^{2}$ \\ 1 School of Chemistry, Sun Yat-sen University, Guangzhou 510275, China; liu21645@163.com \\ 2 Shenzhen Key Laboratory of Polymer Science and Technology, College of Materials Science and Engineering, \\ Shenzhen University, Shenzhen 518060, China; pancj@szu.edu.cn \\ 3 Weldon School of Biomedical Engineering, Birck Nanotechnology Center, Center for Implantable Devices, \\ Purdue University, West Lafayette, IN 47907, USA; xu.jinjia515@hotmail.com \\ * Correspondence: xiedx9@mail.sysu.edu.cn
}

Received: 9 May 2020; Accepted: 27 June 2020; Published: 30 June 2020

check for updates

\begin{abstract}
TE) properties of organic semiconductors. Understanding the relationship between the structure-propertyfunction can help us screen valuable materials. In this study, we designed and synthesized a series of conjugated copolymers (P1, P2, and P3) based on an indacenodithiophene (IDT) building block. A copolymer (P3) with an alternating donor-acceptor (D-A) structure exhibits a narrower band gap and higher carrier mobility, which may be due to the D-A structure that helps reduce the charge carrier transport obstacles. In the end, its power factor reaches $4.91 \mu \mathrm{W} \mathrm{m}{ }^{-1} \mathrm{~K}^{-2}$ at room temperature after doping, which is superior to those of non-D-A IDT-based copolymers (P1 and P2). These results indicate that moderate adjustment of the polymer backbone is an effective way to improve the TE properties of copolymers.
\end{abstract}

Keywords: organic thermoelectric materials; conjugated polymer; indacenodithiophene (IDT); backbone engineering

\section{Introduction}

Thermoelectric (TE) materials, which can directly convert thermal energy into electrical energy, provide an environmentally friendly method for energy utilization [1-4]. At present, the research directions of TE materials are mainly divided into inorganic TE and organic TE (OTE) materials [5,6]. Compared with traditional inorganic TE materials, OTE materials has good mechanical flexibility and easy to process, giving them high potential applicability for wearable and large-area applications [7-9]. The thermal conversion efficiency of TE materials mainly depends on the size of the dimensionless figure of merit $(Z T), Z T=S^{2} \sigma T / \kappa$, where $S$ is the Seebeck coefficient (thermopower), $\sigma$ is the electrical conductivity, $T$ is the absolute temperature, and $\kappa$ is the thermal conductivity. OTE materials usually have low $\kappa$ values $\left(0.1-0.5 \mathrm{~W} \mathrm{~m}^{-1} \mathrm{~K}^{-1}\right)$; therefore, the study of OTE materials is mainly focused on improving the value of the power factor $\left(S^{2} \sigma\right)$ [7].

Proper chemical doping for conjugated polymers (CPs) is an effective way to improve charge injection [10,11], such as doped CPs that can be used as conductive interlayers for organic light-emitting diodes (OLEDs) [12] and solar cells [13]. Similarly, chemical doping in an OTE material (i.e., by introducing a molecule that oxidizes or reduces copolymers to generate a free charge carrier) is also important [14]. During the doping process, the charge carrier transfers between dopants and polymers, and the concentration or mobility of the internal carriers will influence the Seebeck coefficient and electrical conductivity of CPs [15]. Recently, there are several reports of investigating the chemical doping process to improve the TE properties of CPs [16-19] For example, Jang et al. reported the 
F4TCNQ-doped $4 H$-cyclopenta[2,1-b:3,4- $b^{\prime}$ ]dithiophene-based polymer (PCDTFBT) can achieve a high power factor up to $31.5 \mu \mathrm{W} \mathrm{m}^{-1} \mathrm{~K}^{-2}$ [20]. Yee et al. synthesized poly(3-alkylselenophenen) (P3RSe) to achieve a high power factor of $13 \mu \mathrm{W} \mathrm{m}^{-1} \mathrm{~K}^{-2}$ at higher dopant concentrations $\left(\mathrm{FeCl}_{3} \approx 5 \times 10^{-3} \mathrm{M}\right)$ [19].

Although polymer doping has made great achievements, further developments in understanding the relationship between polymer structures and properties (e.g., carrier mobility, TE performance, and power conversion efficiency) are highly desirable to help us screen out valuable materials [20-23]. Moreover, a conjugated backbone is the basic unit that determines carrier mobility in CPs, by adjusting the intrinsic energy level and charge transfer efficiency between the CPs and dopants [24]. In addition, according to the continuous development of organic thermoelectric materials in recent years, enhanced thermoelectric performance has been obtained, but the reported results are mainly focused on the traditional conjugated polymers such as poly(3,4-ethylenedioxythiophene) (PEDOT), polypyrrole (PPy) and polyaniline (PANI). Ouyang, et al. recently reported the highest PF of PEDOT-PSS system which reached $155 \mathrm{~mW} / \mathrm{m}^{-1} \mathrm{~K}^{2}$ [25]. The limitations of raw materials limit the development to a certain extent, therefore the screening of new potential thermoelectric materials are necessary for the discovery of high performance organic thermoelectric materials.

Herein, we selected the indacenodithiophene (IDT) building block as the OTE material since the IDT skeleton has two thiophene rings attached with a central benzene ring that provide strong intermolecular interactions with ordered packing [26-28], which is beneficial for improving the electrical conductivity of OTE materials. IDT-based polymers have been widely used in organic field effect transistor (OFET) and solar cell applications [29-31]; however, although research on its TE properties has also been reported [32,33], the TE performance is still very low, and the detailed structure-property relationships are not comprehensive. In addition, we have recently reported IDT-based composite thermoelectric materials and found that the composites showed good performance with power factor of $161.34 \mathrm{~mW} / \mathrm{m}^{-1} \mathrm{~K}^{2}$ [34].

In this work, we synthesized three IDT-based alternating copolymers P1, P2, and P3 with different backbone structures to investigate the relationship between the structure-property and the chemical doping mechanism (Figure 1). Through a series of characterizations, we found that P3 with D-A structure exhibits a two orders of magnitude higher carrier mobility $\left(3.54 \times 10^{-3} \mathrm{~cm}^{2} \mathrm{~V}^{-1} \mathrm{~s}^{-1}\right)$ than that of $\mathbf{P} 1$ and $\mathbf{P 2}$, and the higher carrier mobility makes $\mathbf{P} \mathbf{3}$ to exhibit a higher electrical conductivity. The maximum power factor of $\mathbf{P} 3$ reached $4.91 \mu \mathrm{W} \mathrm{m}{ }^{-1} \mathrm{~K}^{-2}$ after p-type doping with $\mathrm{FeCl}_{3}$ at room temperature, which was much higher than the TE properties of $\mathbf{P 1}$ and $\mathbf{P 2}$. These results indicate that the manipulation of CPs backbone structure is a promising strategy to develop high performance TE materials.

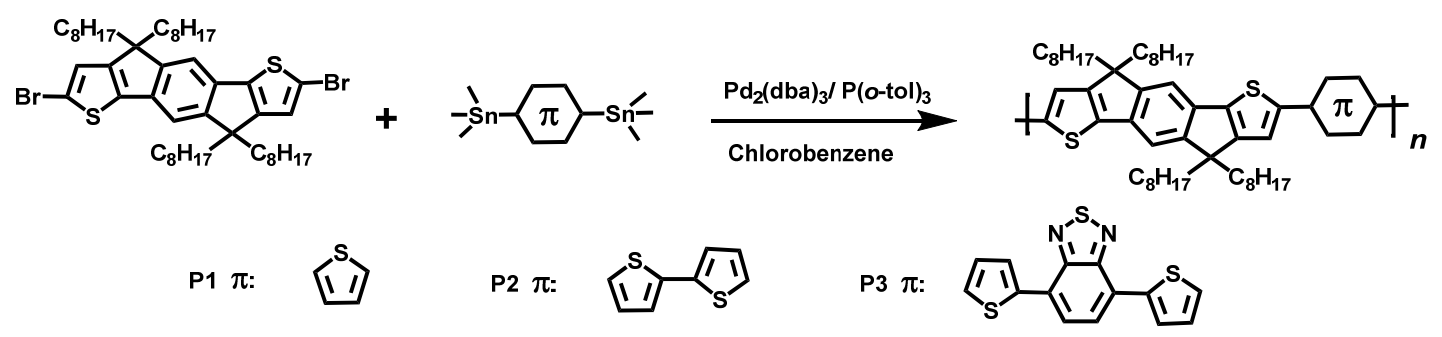

Figure 1. Chemical structures of the IDT unit and its copolymers.

\section{Experimental Section}

\subsection{Materials}

2,7-Dibromo-4,4,9,9-tetraoctyl-4,9-dihydro-s-indaceno[1,2-b:5,6-b' '] dithiophene, 2,5-bis(trimethylstannyl) thiophene, 2,2'-bis(trimethylstannyl)-5,5'-dithiophene and 4,7-bis(2-trimethylstannylthien-5-yl)-2,1,3benzothiadiazole were purchased from Suna Tech Inc. (Suzhou, China). Tris(2-methylphenyl)phosphine $\left(\mathrm{P}(o-\mathrm{tol})_{3}\right)$ and tris(dibenzylideneacetone) dipalladium $(0)\left(\mathrm{Pd}_{2}\left(\mathrm{dba}_{3}\right)\right.$ were purchased from Greenchem Technlogy Co., Ltd. (Beijing, China). Anhydrous chlorobenzene $(\mathrm{PhCl})$ and ferric chloride $\left(\mathrm{FeCl}_{3}\right)$ 
were obtained from Sun Chemical Technology Co., Ltd. (Shanghai, China). Other chemical reagentsincluding deionized water, methanol, acetone, chlorobenzene, dichloromethane, and acetonitrile-were obtained from commercial sources, and all reagents were used without further treatment unless otherwise noted.

\subsection{Synthesis of Polymers}

\subsubsection{General Synthetic Procedure}

A mixture of 2,7-dibromo-4,4,9,9-tetraoctyl-4,9-dihydro-s-indaceno[1,2-b:5,6-b']dithiophene ( $0.200 \mathrm{~g}, 0.229 \mathrm{mmol})$, bis(trimethylstannyl) compound $(0.229 \mathrm{mmol}), \mathrm{Pd}_{2}(\mathrm{dba})_{3}(0.011 \mathrm{~g}, 0.011 \mathrm{mmol})$ and $\mathrm{P}(o \text {-tol })_{3}(0.018 \mathrm{~g}, 0.057 \mathrm{mmol})$ in anhydrous chlorobenzene $(5 \mathrm{~mL})$ with a nitrogen flow was sealed and stirred for $72 \mathrm{~h}$ at $110^{\circ} \mathrm{C}$. After the mixture was cooled to room temperature, the polymer was precipitated by the addition of excess methanol. The precipitate was sequentially washed with methanol, acetone, and deionized water. After dried under vacuum, the polymer was obtained.

2.2.2. 2-Methyl-7-(5-methylthiophen-2-yl)-4,4,9,9-tetraoctyl-4,9-dihydro-s-indaceno[1,2-b:5,6-b'] dithiophene (P1)

Brown solid (0.16 g, 66\%). ${ }^{1} \mathrm{H}$ NMR (600 MHz, $\left.\mathrm{CDCl}_{3}\right): \delta / \mathrm{ppm} 0.79-0.86\left(\mathrm{t}, 12 \mathrm{H}, \mathrm{C}_{3}\right), 1.03-1.29$ $\left(\mathrm{m}, 48 \mathrm{H}, \underline{\mathrm{C}}_{2}\right), 1.96\left(\mathrm{~d}, 8 \mathrm{H}, \underline{\mathrm{C}}_{2}\right), 7.06-7.26\left(\mathrm{~m}, 6 \mathrm{H}\right.$, aromatic). Analysis calculated for $\mathrm{C}_{52} \mathrm{H}_{74} \mathrm{~S}_{3}: \mathrm{C}$, 78.53; H, 9.38; S, 12.09. Found: C, 76.91; H, 10.19; S, 11.75 .

2.2.3. 2-Methyl-7-(5'-methyl-[2,2'-dithiophen]-5-yl)-4,4,9,9-tetraoctyl-4,9-dihydro-s-indaceno[1,2-b:5, 6-b']dithiophene (P2)

Brown solid (0.20 g, 76\%). ${ }^{1} \mathrm{H}$ NMR of $\mathbf{P 2}\left(600 \mathrm{MHz}, \mathrm{CDCl}_{3}\right): \delta / \mathrm{ppm} 0.81-0.84\left(\mathrm{t}, 12 \mathrm{H}, \mathrm{C}_{3}\right)$, 0.85-1.33 (m, 48H, $\left.\mathrm{CH}_{2}\right), 1.95\left(\mathrm{~d}, 8 \mathrm{H}, \mathrm{CH}_{2}\right), 6.99-7.20(\mathrm{~m}, 6 \mathrm{H}$, thiophene), 7.21-7.26 (s, $2 \mathrm{H}$, aromatic). Analysis calculated for $\mathrm{C}_{56} \mathrm{H}_{76} \mathrm{~S}_{4}$ : $\mathrm{C}, 76.65 ; \mathrm{H}, 8.73 ; \mathrm{S}, 14.61$. Found: $\mathrm{C}, 76.42 ; \mathrm{H}, 9.65 ; \mathrm{S}, 14.26$.

2.2.4. 4-(5-(7-methyl-4,4,9,9-tetraoctyl-4,9-dihydro-s-indaceno[1,2-b:5,6-b']dithiophen-2-yl)thiophen2-yl)-7-(5-methylthiophen-2-yl)benzo[c][1,2,5]thiadiazole (P3)

Black solid (0.24 g, 84\%). ${ }^{1} \mathrm{H}$ NMR (600 MHz, $\left.\mathrm{CDCl}_{3}\right)$ : $\delta / \mathrm{ppm} 0.80-0.87\left(\mathrm{t}, 12 \mathrm{H}, \mathrm{C}_{3}\right), 0.87-1.51$ $\left(\mathrm{m}, 48 \mathrm{H}, \underline{\mathrm{CH}}_{2}\right), 1.94\left(\mathrm{~d}, 8 \mathrm{H}, \underline{\mathrm{CH}}_{2}\right), 7.22(\mathrm{~s}, 2 \mathrm{H}$, aromatic), 7.27-7.47 $(\mathrm{m}, 4 \mathrm{H}$, thiophene), $7.92(\mathrm{~s}, 2 \mathrm{H}$, thiophene), 8.08 (s, 2H, aromatic). Analysis calculated for $\mathrm{C}_{62} \mathrm{H}_{78} \mathrm{~N}_{2} \mathrm{~S}_{5}: \mathrm{C}, 73.61 ; \mathrm{N}, 2.77 ; \mathrm{H}, 7.77 ; \mathrm{S}$, 15.85. Found: C, 72.84; N, 2.53; H, 8.47; S, 15.54 .

\subsection{Preparation of Polymer Films}

$\mathbf{P 1}, \mathbf{P 2}$, and $\mathbf{P 3}$ were dissolved in a chlorobenzene at a concentration of $5 \mathrm{mg} \mathrm{mL}^{-1}$. The pristine polymer films were obtained by drop-casting the solution onto glass substrates $(10 \times 10 \mathrm{~mm}$, washed sequentially with dichloromethane, ethanol, acetone, and isopropanol for $30 \mathrm{mins}$ ) under ambient conditions. Film thicknesses of the prepared samples are ranged from $6 \mu \mathrm{m}$ to $8 \mu \mathrm{m}$.

\subsection{Doping Experiment}

$\mathrm{FeCl}_{3}$ was dissolved in acetonitrile at a concentration of $0.1 \mathrm{M}$. The pristine polymer films were immersed in the $\mathrm{FeCl}_{3}$ solution for different times $(1,5,10,15,20$, and $30 \mathrm{~min})$ under ambient conditions. Finally, the residual $\mathrm{FeCl}_{3}$ on the surface of the films was rinsed off with methanol.

\section{Results and Discussion}

P1, P2, and P3 were synthesized by Stille coupling as shown in Figure 1. The structures of the polymers were confirmed by ${ }^{1} \mathrm{H}$ NMR (Figure S1). The molecular weights of three polymers were determined by gel permeation chromatography (GPC), and the number-average molecular weights $\left(M_{n}\right)$ of P1, P2, and P3 were found to be 52.8, 53.7, and $58.5 \mathrm{kDa}$, respectively (Figure S2). The thermal 
stability of the polymers was measured by thermal gravimetric analysis (TGA), as shown in Figure S3a, the decomposition temperature $\left(T_{\mathrm{d}}\right.$, the $5 \%$ weight loss) of all polymers exceeded $380{ }^{\circ} \mathrm{C}$, indicating their good thermal stability. In particular, P3 exhibits the highest thermal stability, most likely due to its rigid skeleton (Figure S3b and Table S1).

\subsection{Optical and Electrochemical Characteristics}

UV-vis-NIR absorption spectra of the three polymers in the non-doped thin-film state are shown in Figure 2a. Both P1 and P2 possessed similar spectral profiles with absorption maxima at 542 nm (P1) and $511 \mathrm{~nm}(\mathbf{P 2})$, while $\mathbf{P} 3$ exhibited two absorption peaks, the peak at $444 \mathrm{~nm}$ corresponds to the $\pi-\pi^{*}$ transition and the other peak at $625 \mathrm{~nm}$ should be attributed to the intramolecular charge transfer (ICT) from the electron-rich IDT segment to the electron-deficient benzothiadiazole unit [35,36]. The optical band gap $\left(E_{\mathrm{g}}{ }^{\mathrm{opt}}\right)$ values of the three polymers were calculated to be $2.02 \mathrm{eV}(\mathbf{P 1}), 2.00 \mathrm{eV}(\mathbf{P 2})$, and $1.70 \mathrm{eV}$ (P3), respectively. Cyclic voltammetry (CV) (Figure 2b) was performed to determine the highest occupied molecular orbital (HOMO) $\left(E_{\mathrm{HOMO}}\right)$ and the lowest unoccupied molecular orbital (LUMO) $\left(E_{\mathrm{LUMO}}\right)$ of the polymers according to the above-mentioned formula. The $E_{\mathrm{HOMO}} / E_{\mathrm{LUMO}}$ values of P1, $\mathbf{P 2}$, and P3 were calculated to be $-5.77 /-3.21 \mathrm{eV},-5.78 /-3.28 \mathrm{eV}$, and $-5.77 /-3.49 \mathrm{eV}$, respectively. It is clear to see that all the three polymers exhibit relatively deep HOMO energy levels. The $E_{\mathrm{g}}{ }^{\text {ec }}$ values of P1, P2, and P3 were calculated to be 2.56, 2.50, and $2.28 \mathrm{eV}$, respectively (Table 1), which are in consistent with the trend of their optical bandgaps. The difference between the band gaps obtained by the two test methods is in accordance with the trend reported in the previous literature [37]. The relatively narrower bandgap of $\mathbf{P} 3$ should be attributed to the charge transfer, providing the polymer to have a long effective conjugation length with more delocalized $\pi$-electrons [26].
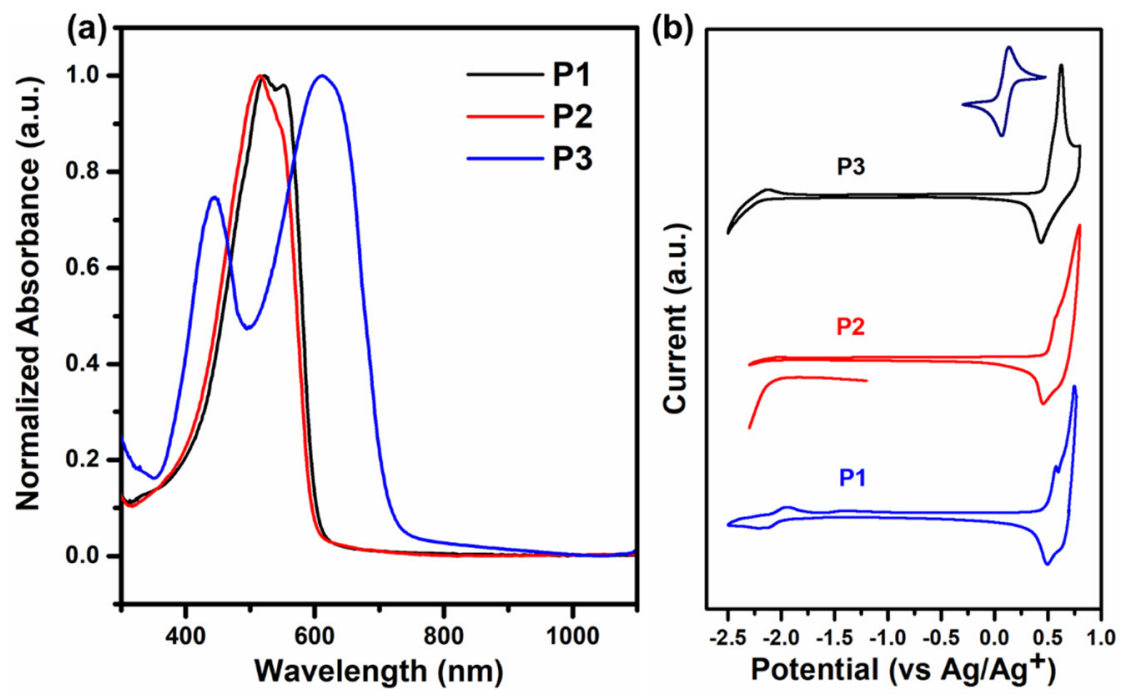

Figure 2. (a) UV-vis-NIR absorption spectra of non-doped P1-P3 in film states. (b) Cyclic voltammograms of P1-P3 in drop-casted films (the reduction peak of $\mathbf{P 2}$ is amplified separately).

To further understand the electrochemical properties of the polymers and the distribution of delocalized electrons, we performed density functional theory (DFT) calculations on model dimers (Figure 3). The HOMO energy of the three polymers has similar delocalization electron distribution on the backbone, which means that the introduction of acceptor into the backbone of P3 will not affect the delocalization electron distribution of HOMO energy. In contrast, the LUMO levels of P1 and P2 are delocalized on the entire polymer backbone, while the LUMO level of P3 is mainly focused on the benzothiadiazole unit with electron deficient feature. The calculated LUMO levels for the three polymers were $-2.00,-2.10$, and $-2.70 \mathrm{eV}$, respectively, we can see that $\mathbf{P} 3$ showed a significantly deeper LUMO level compared to that of other two polymers, suggesting that the introduction of the D-A structure can deepen the LUMO energy to reduce the band gap (Table 1). These results are in good 
agreement with the experimental values from the $\mathrm{CV}$ measurements (i.e., $E_{\mathrm{g}}{ }^{\mathrm{ec}}$ ). The side geometries of the polymers revealed the highly planar backbone features, which provides more evidence for the planar structure of three polymers that can facilitate the transfer of intermolecular charge carriers [24].

Table 1. Optical and electrochemical properties of the copolymers.

\begin{tabular}{|c|c|c|c|c|c|c|c|}
\hline Polymer & $\begin{array}{c}E_{\text {HOMO }} \\
(\mathrm{eV})\end{array}$ & $\begin{array}{c}E_{\text {LUMO }} \\
(\mathrm{eV})\end{array}$ & $\begin{array}{l}E_{\mathrm{g}}{ }^{\mathrm{ec}} \\
(\mathrm{eV})\end{array}$ & $\begin{array}{l}E_{\mathrm{g}} \text { opt } \\
(\mathrm{eV})\end{array}$ & $\begin{array}{c}\lambda_{\text {onset }} \\
\text { (nm) }\end{array}$ & $\begin{array}{c}E_{\mathrm{g}} \mathrm{DFT} \\
(\mathrm{eV})\end{array}$ & $\begin{array}{l}\text { Carrier Mobility } \\
\left(10^{-5} \mathrm{~cm}^{2} \mathrm{v}^{-1} \mathrm{~s}^{-1}\right)\end{array}$ \\
\hline P1 & -5.77 & -3.21 & 2.56 & 2.02 & 613 & 2.50 & 3.48 \\
\hline P2 & -5.78 & -3.28 & 2.50 & 2.00 & 617 & 2.40 & 13.35 \\
\hline P3 & -5.77 & -3.49 & 2.28 & 1.70 & 730 & 2.10 & 354 \\
\hline
\end{tabular}

$E_{\mathrm{g}}{ }^{\mathrm{ec}}$ : Electrochemical band gap. $E_{\mathrm{g}}{ }^{\text {opt }}$ : Optical band gap. $\lambda_{\text {onset }}$ : Onset wavelength of the maximum absorption wavelength. $E_{\mathrm{HOMO}}=-\left(E_{\mathrm{Ox}}-E_{1 / 2}\left({ }_{\mathrm{Fc} / \mathrm{Fc}+)}\right) \mathrm{eV}+(-5.39 \mathrm{eV}), E_{\mathrm{LUMO}}=-\left(E_{\mathrm{red}}-E_{1 / 2}(\mathrm{Fc} / \mathrm{Fc}+)\right) \mathrm{eV}+(-5.39 \mathrm{eV})\right.$, $E_{\mathrm{g}}{ }^{\mathrm{ec}}=E_{\mathrm{LUMO}}-E_{\mathrm{HOMO}}$, (Assuming that the formal potential of ferrocene is at $0.40 \mathrm{~V}$ versus SCE and that $0.24 \mathrm{~V}$ vs. NHE corresponds to $0.0 \mathrm{~V}$ vs. SCE, then the calibration value for ferrocene is $-5.39 \mathrm{eV}$ ) [38].

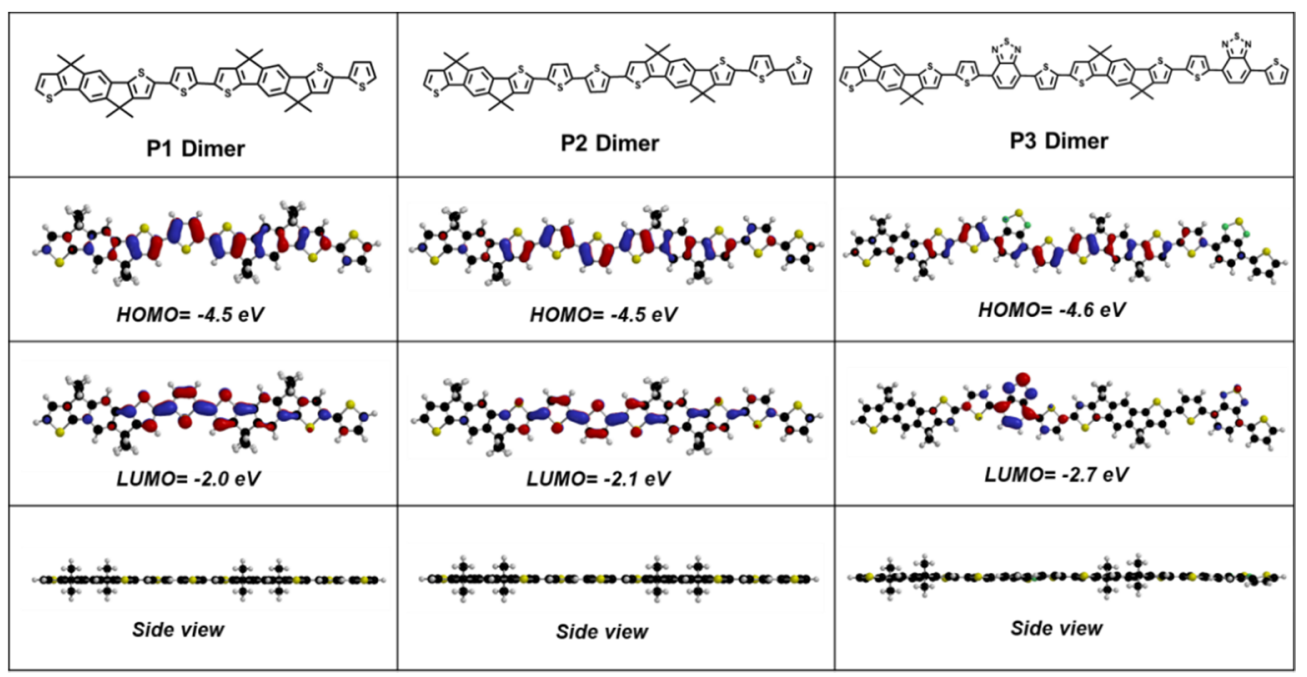

Figure 3. Molecular geometries and theoretical calculations for HOMO and LUMO energy levels of the model dimers of three polymers by density functional theory (DFT) calculations at the B3LYP/6-31G $(d, p)$ level (The alkyl chain is replaced by the methyl group for clarity).

To investigate the mobilities of three polymers, we fabricated simple OFET devices without any optimizations (Figures S4 and S5), and the field effect mobility of the non-doped polymers was determined to be $3.48 \times 10^{-5}(\mathbf{P 1}), 13.35 \times 10^{-5}(\mathbf{P 2})$, and $3.54 \times 10^{-3} \mathrm{~cm}^{2} \mathrm{~V}^{-1} \mathrm{~s}^{-1}(\mathbf{P} 3)$. Although the mobility of $\mathbf{P} \mathbf{3}$ is lower compared to the reported values in the previous reports due to the immature OFET devices [26], P3 exhibited the highest carrier mobility among the three polymers investigated in this work, which is mainly due to its flat aromatic structure that can facilitate the intermolecular packing, thus enhancing the charge carrier transporting. Generally, CPs with higher carrier mobility is beneficial to larger electrical conductivity and higher is beneficial to larger Seebeck coefficients [39].

UV-vis-NIR spectroscopy was also performed to investigate the extent of doping of the three polymers. As shown in Figure 4, after doping, new absorption peaks appeared at 872 (P1), 846 (P2), and $882 \mathrm{~nm}(\mathbf{P 3})$ respectively with a broad peak at a wavelength over $1100 \mathrm{~nm}$ were observed, which should be generated from the formation of polarons [40,41]. As the doping time increased, the concentration of polarons were simultaneously increased. 

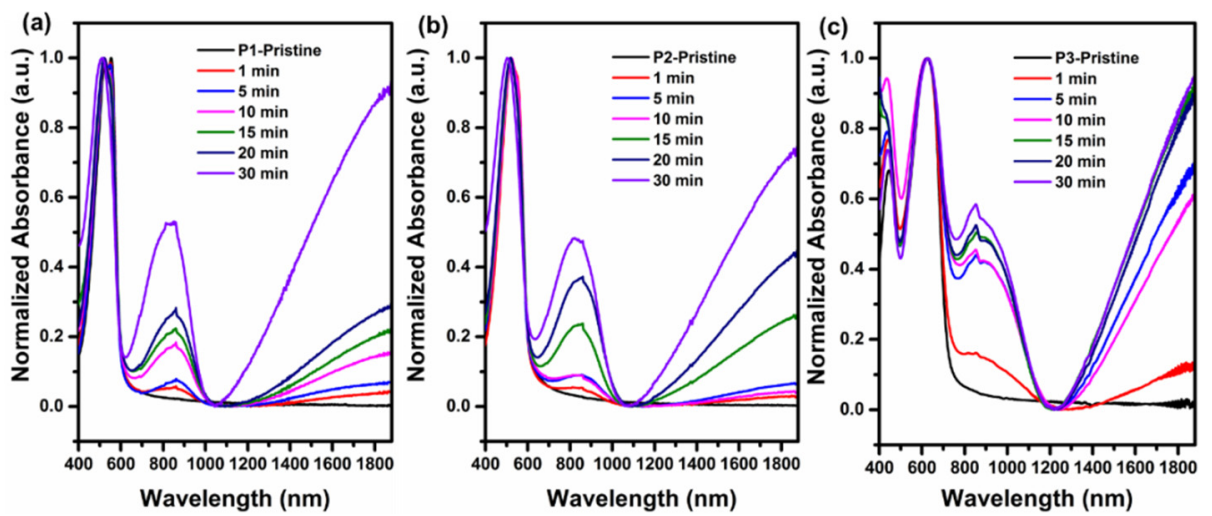

Figure 4. Time dependence of normalized UV-vis-NIR absorption spectra of polymer films doped with $\mathrm{FeCl}_{3}$ : P1 (a), P2 (b), and P3 (c).

\subsection{Thin-Film Microstructure}

The introduction of dopants to polymer films usually causes microscopic changes in surface morphology, resulting in different localizations of the charge carriers in the polymers films [42]. Through GI-XRD and POM (Figure S6) analyses, we found that all three polymers are paracrystalline (see Supporting Information for details). As shown in Figure 5, the root mean square (RMS) values of the polymer films were obtained as follows: P1 $(2.98 \mathrm{~nm}), \mathbf{P 2}(2.33 \mathrm{~nm})$, and P3 (1.71 nm). P3 exhibited a relatively smoother morphology compared to that of P1 and P2. After doping (immersed in $0.1 \mathrm{M}$ $\mathrm{FeCl}_{3}$ /acetonitrile for $\left.15 \mathrm{mins}\right)$, all the three polymer films showed increased RMS values (P1 $(3.71 \mathrm{~nm})$, $\mathbf{P 2}(2.44 \mathrm{~nm})$, and $\mathbf{P 3}(4.01 \mathrm{~nm}))$. It can be found that the surface roughness of P1 and P2 films only slightly increases after doping, compared to the roughness of $\mathbf{P} 3$ films, which indicates that the stability of the morphology of $\mathbf{P 1}$ and $\mathbf{P 2}$ films during doping is higher than that of P3 films. From the SEM (Figure S7), we can intuitively see that the surface of the polymer film after doping is still smooth. In the EDS (Figure S7), we also see that the residual iron element on the surface is evenly distributed without forming any aggregation, which also indicates that the $\mathrm{FeCl}_{3}$ doped the polymer uniformly.
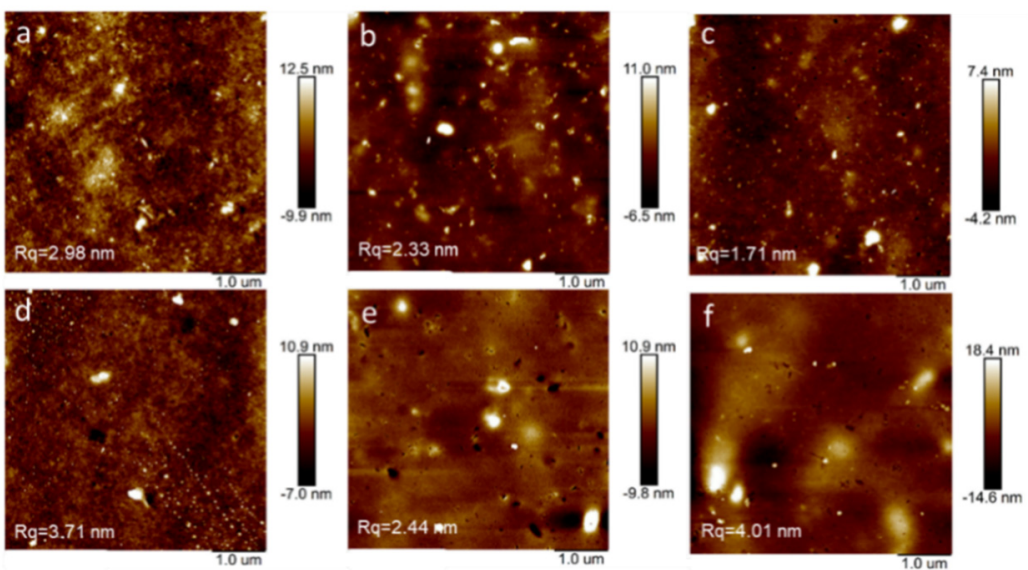

Figure 5. AFM images of P1 (a), P2 (b), and P3 (c) pristine films and P1 (d), P2 (e), and P3 (f) films doped with $\mathrm{FeCl}_{3}(0.1 \mathrm{M})$ for $15 \mathrm{~min}$.

\subsection{Thermoelectric Performance}

To compare the different TE properties, the pristine polymer films were immersed in $0.1 \mathrm{M}$ $\mathrm{FeCl}_{3}$ /acetonitrile for different doping times. We performed the measurements for multiple times under the same condition to ensure the reproducibility of the data. As shown in Figure 6, the Seebeck coefficient $(S)$ and electrical conductivity $(\sigma)$ showed opposite trends due to the enhanced concentration of polarons. After doping the polymers for 15 mins, P1, P2, and P3 showed $\sigma$ values of $0.64,4.80$, 
and $9.65 \mathrm{~S} \mathrm{~cm}^{-1}$, respectively. In the meantime, $\mathbf{P} 3$ exhibited the largest value of Seebeck coefficient $(S)$ $\left(71.26 \mu \mathrm{V} \mathrm{K}^{-1}\right)$ compared to those of P1 $\left(49.73 \mu \mathrm{V} \mathrm{K}^{-1}\right)$ and $\mathbf{P 2}\left(54.19 \mu \mathrm{V} \mathrm{K}^{-1}\right)$. Therefore, P3 showed the largest $\mathrm{PF}$ value of $4.91 \mu \mathrm{W} \mathrm{m}{ }^{-1} \mathrm{~K}^{-2}$. In addition, we compared the recently reported thermoelectric properties of organic matter as shown in Table S2. Obviously, it should be noted that our material still has a certain gap compared with the composite TE material, but it shows higher TE performance compared with the performance of pristine polymer TE material after doping. Indicating that IDT-based conjugated polymers are promising materials for TE applications.
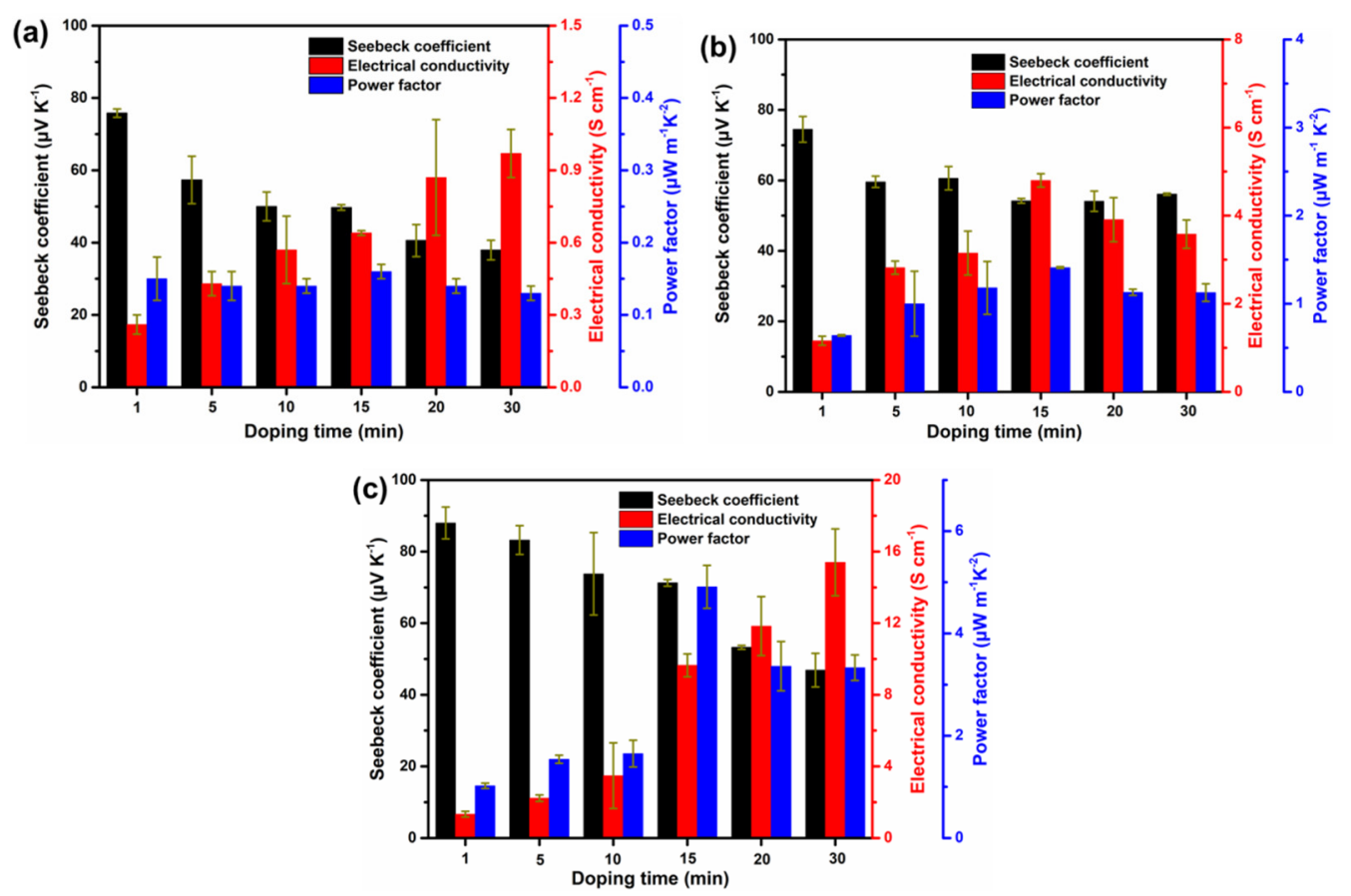

Figure 6. Thermoelectric performance for P1 (a), P2 (b), and P3 (c) films with different doping times (immersed in the $0.1 \mathrm{M} \mathrm{FeCl}_{3}$ /acetonitrile) at room temperature.

\subsection{Photoelectron Spectroscopy}

We investigated the electronic structure and doping mechanism of polymers through X-ray photoelectron spectroscopy (XPS) and ultraviolet photoelectron spectroscopy (UPS) (Figure 7). Compared to the results from the non-doped polymer, a new $\mathrm{C} 11$ s peak derived from the dopant $\mathrm{FeCl}_{3}$ was observed. More importantly, the peaks of S 2s for P1 and $\mathbf{P 2}$ and S 2s and N 1s for P3 (Figure S8) shifted toward a larger binding energy caused by the electron transfer occurs between the polymers and dopant [43]. This result proves that chemical doping of the polymer by $\mathrm{FeCl}_{3}$ is mainly achieved by oxidation of the bonding atoms in the polymer. In the UPS spectra (Figure S9), we found all the three polymers exhibited two different characteristic peaks. The peak in the range of $17.53-14.65 \mathrm{eV}$ belongs to inelastic elastic electron scattering, and the peak in the range of 12.43-5.38 eV corresponds to the $\sigma$ peak of the system [44]. Figure $7 \mathrm{~b}$ shows the UPS secondary electron cut-off region of the polymer films in pristine and doped conditions. According to the formula (work function $\emptyset=21.2-E_{\text {cutoff }} \mathrm{eV}$ ), the work functions of P1, P2, and $\mathbf{P} 3$ were calculated to be 4.24, 3.94, and $3.93 \mathrm{eV}$, respectively. For the secondary cutoff of the polymers, the voltage shifted to a smaller binding energy after doping, resulting in an increase in the work function (P1(4.72 eV), P2 $(4.86 \mathrm{eV})$, and P3 $(4.93 \mathrm{eV}))$. Combined with the energy level structure diagram shown in Figure S10, we conclude that the Fermi level moves towards the HOMO direction when the work function increases, indicating the generation of hole carriers, and also proves that $\mathrm{FeCl}_{3}$ is a p-type dopant for P1, P2, and P3 [35,43]. The ionization energy (IE = $\varnothing+$ valence band (or HOMO) onset) [45] of P1, P2, and P3 is 5.10, 5.01, and $5.18 \mathrm{eV}$, respectively (Figure S9d); the electron affinity of $\mathrm{FeCl}_{3}$ is $4.62 \mathrm{eV}$ as documented in previous reports [11]. 
For p-dopable polymers, the doping efficiency should generally increase as the $\mathrm{IE}_{\text {polymer }}-(\mathrm{EA})_{\text {dopant }}$ difference increases, resulting in a larger thermodynamic driving force for polymer oxidation $[46,47]$, therefore $\mathbf{P} 3$ with the largest $\mathrm{HOMO}$ onset binding energy shows the best thermoelectric performance.
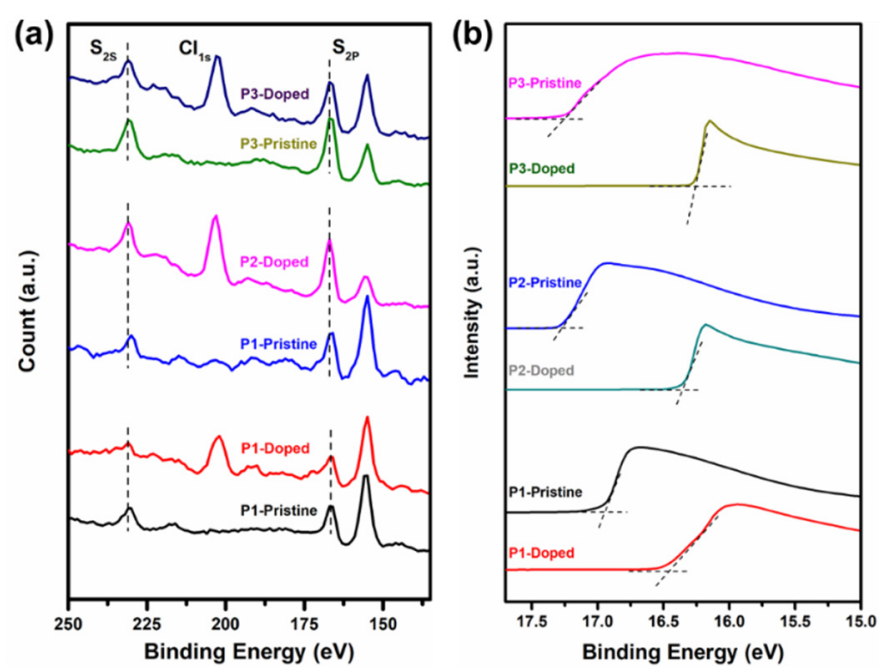

Figure 7. (a) XPS spectra S $2_{S}$ and S 2 P curves of pristine polymer films and films doped with $\mathrm{FeCl}_{3}$ $(0.1 \mathrm{M})$ for $15 \mathrm{~min}$; $(\mathbf{b})$ UPS spectra (He I $\alpha$ radiation, photon energy $=21.22 \mathrm{eV}$ ) showing the secondary electron cut-off region for polymers in pristine and films doped with $\mathrm{FeCl}_{3}(0.1 \mathrm{M})$ for $15 \mathrm{~min}$.

\section{Conclusions}

In this work, we synthesized three different IDT-based conjugated copolymers, P1, P2, and P3, to study how conjugated backbones affect the TE performances. We found that P3 with a D-A alternating backbone exhibited a narrower band gap and higher carrier mobility than those of the other two polymers. Under the same doping conditions, P3 showed the highest doping efficiency, which facilitates the charge transfer between the polymer and the dopant. As a result, P3 exhibited a maximum PF of $4.91 \mu \mathrm{W} \mathrm{m}{ }^{-1} \mathrm{~K}^{-2}$ at room temperature. These results prove that the IDT-based copolymers show great prospective applications as OTE materials, and a suitable backbone structural design is important for improving the TE properties.

Supplementary Materials: The following are available online at http://www.mdpi.com/2073-4360/12/7/1463/s1.

Author Contributions: D.X. and C.P. conceived and designed the experiments; T.L. performed the experiments; J.X. and T.L. analyzed the data; J.X. contributed reagents/materials/analysis tools; T.L. wrote the paper. All authors have read and agreed to the published version of the manuscript.

Funding: This work was financially supported by the Fundamental Research Funds for the Central Universities (19lgpy140, 20lgpy89) and Science Foundation of Guangdong Province (No. 2018A0303130157).

Conflicts of Interest: The authors declare no conflict of interest.

\section{References}

1. Zhang, F.; Zang, Y.; Huang, D.; Di, C.A.; Zhu, D. Flexible and self-powered temperature-pressure dual-parameter sensors using microstructure-frame-supported organic thermoelectric materials. Nat. Commun. 2015, 6, 8356. [CrossRef] [PubMed]

2. Li, C.; Jiang, F.; Liu, C.; Wang, W.; Li, X.; Wang, T.; Xu, J. A simple thermoelectric device based on inorganic/organic composite thin film for energy harvesting. Chem. Eng. J. 2017, 320, 201-210. [CrossRef]

3. Liang, L.; Gao, C.; Chen, G.; Guo, C.-Y. Large-area, stretchable, super flexible and mechanically stable thermoelectric films of polymer/carbon nanotube composites. J. Mater. Chem. C 2016, 4, 526-532. [CrossRef]

4. Poehler, T.; Katz, H. Prospects for polymer-based thermoelectrics: State of the art and theoretical analysis. Energy Environ. Sci. 2012, 5, 8110. [CrossRef] 
5. Chen, G.; Xu, W.; Zhu, D. Recent advances in organic polymer thermoelectric composites. J. Mater. Chem. C 2017, 5, 4350-4360. [CrossRef]

6. Bubnova, O.; Crispin, X. Towards poly mer-based organic thermoelectric generators. Energy Environ. Sci. 2012, 5, 9345. [CrossRef]

7. Zhang, Q.; Sun, Y.; Xu, W.; Zhu, D. Organic thermoelectric materials: Emerging green energy materials converting heat to electricity directly and efficiently. Adv. Mater. 2014, 26, 6829-6851. [CrossRef]

8. Jiang, Q.; Lan, X.; Liu, C.; Shi, H.; Zhu, Z.; Zhao, F.; Xu, J.; Jiang, F. High-performance hybrid organic thermoelectric SWNTs/PEDOT: PSS thin-films for energy harvesting. Mater. Chem. Front. 2018, 2, 679-685. [CrossRef]

9. Russ, B.; Glaudell, A.; Urban, J.J.; Chabinyc, M.L.; Segalman, R.A.; Chabinyc, R.A. Segalman, Organic thermoelectric materials for energy harvesting and temperature control. Nat. Rev. Mater. 2016, 1, 16050. [CrossRef]

10. Walzer, K.; Maenning, B.; Pfeiffer, M.; Leo, K. Highly Efficient Organic Devices Based on Electrically Doped Transport Layers. Chem. Rev. 2007, 107, 1233-1271. [CrossRef] [PubMed]

11. Liang, Z.; Zhang, Y.; Souri, M.; Luo, X.; Boehm, A.M.; Li, R.; Zhang, Y.; Wang, T.; Kim, D.-Y.; Mei, J.; et al. Influence of dopant size and electron affinity on the electrical conductivity and thermoelectric properties of a series of conjugated polymers. J. Mater. Chem. A 2018, 6, 16495-16505. [CrossRef]

12. Zhao, Y.; Zhao, X.; Roders, M.; Gumyusenge, A.; Ayzner, A.L.; Mei, J. Melt-Processing of Complementary Semiconducting Polymer Blends for High Performance Organic Transistors. Adv. Mater. 2017, 29, 1605056. [CrossRef]

13. Jung, M.; Raga, S.; Ono, L.; Qi, Y. Substantial improvement of perovskite solar cells stability by pinhole-free hole transport layer with doping engineering. Sci. Rep. 2015, 5, 9863. [CrossRef] [PubMed]

14. Suh, E.; Jeong, Y.; Oh, J.; Lee, K.; Jung, J.; Kang, Y.; Jang, J. Doping of donor-acceptor polymers with long side chains via solution mixing for advancing thermoelectric properties. Nano Energy 2019, 58, 585-595. [CrossRef]

15. Zou, Y.; Huang, D.; Meng, Q.; Di, C.; Zhu, D. Correlation between Seebeck coefficient and transport energy level in poly(3-hexylthiophene). Org. Electron. 2018, 56, 125-128. [CrossRef]

16. Aziz, E.; Vollmer, A.; Eisebitt, S.; Eberhardt, W.; Pingel, P.; Neher, D.; Koch, N. Localized Charge Transfer in a Molecularly Doped Conducting Polymer. Adv. Mater. 2007, 19, 3257-3260. [CrossRef]

17. Alveroglu, E. Doping effect of dodecyl benzene sulphonic acid in poly(3-hexylthiophene)-P3HT-films. J. Mol. Struct. 2015, 1086, 86-92. [CrossRef]

18. Gregory, S.; Menon, A.; Ye, S.; Seferos, D.; Reynolds, J.; Yee, S. Effect of Heteroatom and Doping on the Thermoelectric Properties of Poly(3-alkylchalcogenophenes). Adv. Energy Mater. 2018, 8, 1802419. [CrossRef]

19. Thomas, E.; Davidson, E.; Katsumata, R.; Segalman, R.; Chabinyc, M. Branched Side Chains Govern Counterion Position and Doping Mechanism in Conjugated Polythiophenes. ACS Macro Lett. 2018, 7, 1492-1497. [CrossRef]

20. Kroon, R.; Mengistie, D.; Kiefer, D.; Hynynen, J.; Ryan, J.; Yu, L.; Muller, C. Thermoelectric plastics: From design to synthesis, processing and structure-property relationships. Chem. Soc. Rev. 2016, 45, 6147-6164. [CrossRef]

21. Blackburn, J.; Ferguson, A.; Cho, C.; Grunlan, J. Carbon-nanotube-based thermoelectric materials and devices. Adv. Mater. 2018, 30, 1704386. [CrossRef] [PubMed]

22. Huang, D.; Yao, H.; Cui, Y.; Zou, Y.; Zhang, F.; Wang, C.; Shen, H.; Jin, W.; Zhu, J.; Diao, Y.; et al. Conjugated-Backbone Effect of Organic Small Molecules for n-Type Thermoelectric Materials with ZT over 0.2. J. Am. Chem. Soc. 2017, 139, 13013-13023. [CrossRef] [PubMed]

23. Gueye, M.; Carella, A.; Massonnet, N.; Yvenou, E.; Brenet, S.; Faure-Vincent, J.; Pouget, S.; Rieutord, F.; Okuno, H.; Benayad, A.; et al. Structure and Dopant Engineering in PEDOT Thin Films: Practical Tools for a Dramatic Conductivity Enhancement. Chem. Mater. 2016, 28, 3462-3468. [CrossRef]

24. Osaka, I.; McCullough, R. Advances in Molecular design and synthesis of regioregular polythiophene. Acc. Chem. Res. 2008, 41, 1202-1214. [CrossRef] [PubMed]

25. Guan, X.; Feng, W.; Wang, X.; Venkatesh, R.; Ouyang, J. Significant Enhancement in the Seebeck Coefficient and Power Factor of p-Type Poly(3,4-ethylenedioxythiophene):Poly(styrenesulfonate) through the Incorporation of n-Type MXene. ACS Appl. Mater. Interfaces 2020, 12, 13013-13020. [CrossRef] [PubMed] 
26. Havinga, E.; Tenhoeve, W.; Wynberg, H. Alternate donor-acceptor small-band-gap semiconducting polymers; Polysquaraines and polycroconaines. Syntheyic Met. 1993, 55, 299-306. [CrossRef]

27. Zhang, W.; Smith, J.; Watkins, S.; Gysel, R.; McGehee, M.; Salleo, A.; Kirkpatrick, J.; Ashraf, S.; Anthopoulos, T.; Heeney, M. Indacenodithiophene Semiconducting Polymers for High-Performance Air-Stable Transistors. J. Am. Chem. Soc. 2010, 132, 11437-11439. [CrossRef]

28. Venkateshvaran, D.; Nikolka, M.; Sadhanala, A.; Lemaur, V.; Zelazny, M.; Kepa, M.; Hurhangee, M.; Kronemeijer, A.; Pecunia, V.; Nasrallah, I.; et al. Approaching disorder-free transport in high-mobility conjugated polymers. Nature 2014, 515, 384-388. [CrossRef]

29. Chen, K.; Zhang, Y.; Yip, H.; Sun, Y.; Davies, J.A.; Ting, C.; Chen, C.; Jen, A.K. Highly efficient indacenodithiophene-based polymeric solar cells in conventional and inverted device configurations. Org. Electron. 2011, 12, 794-801. [CrossRef]

30. Wang, M.; Wang, H.; Yokoyama, T.; Liu, X.; Huang, Y.; Zhang, Y.; Nguyen, T.Q.; Aramaki, S.; Bazan, G. High open circuit voltage in regioregular narrow band gap polymer solar cells. J. Am. Chem. Soc. 2014, 136, 12576-12579. [CrossRef]

31. Zhang, M.; Guo, X.; Wang, X.; Wang, H.; Li, Y. Synthesis and Photovoltaic Properties of D-A Copolymers Based on Alkyl-Substituted Indacenodithiophene Donor Unit. Chem. Mater. 2011, 23, 4264-4270. [CrossRef]

32. Wu, S.; Wu, X.; Xing, W.; Sun, Y.; Zou, Y.; Xu, W.; Zhu, D. Backbone Structure Effect on the Thermoelectric Properties of IDT-Based p-Type Conjugated Polymers. Macromol. Rapid Commun. 2019, 41, e1900322. [CrossRef] [PubMed]

33. Wei, C.; Wang, L.; Pan, C.; Chen, Z.; Zhao, H.; Wang, L. Effect of backbone structure on the thermoelectric performance of indacenodithiophene-based conjugated polymers. React. Funct. Polym. 2019, 142, 1-6. [CrossRef]

34. Chen, Z.; Liu, T.; Pan, C.; Tan, G. Enhanced Thermoelectric Performance of Indacenodithiophene Benzothiadiazole Copolymer Containing Polar Side Chains and Single Wall Carbon Nanotubes Composites. Polymers 2020, 12, 848. [CrossRef] [PubMed]

35. Huang, H.; Du, Z.; Huang, C.; Zhang, J.; Liu, S.; Fu, N.; Zhao, B.; Yang, R.; Huang, W. Angular/linear-shaped indacenodithiophene (IDT) for donor-acceptor copolymers: Geometric shape effects on physical properties and photovoltaic performance. Polymer 2019, 162, 11-19. [CrossRef]

36. Xu, Y.; Chueh, C.; Yip, H.; Ding, F.; Li, Y.; Li, C.; Li, X.; Chen, W.; Jen, A. Improved charge transport and absorption coefficient in indacenodithieno[3,2-b]thiophene-based ladder-type polymer leading to highly efficient polymer solar cells. Adv. Mater. 2012, 24, 6356-6361. [CrossRef]

37. Zhou, X.; Pan, C.; Gao, C.; Shinohara, A.; Yin, X.; Wang, L.; Li, Y.; Jiang, Q.; Yang, C.; Wang, L. Thermelectrics of two-dimensional conjugated benzodithiophene-based polymers: Density-of-states enhancement and semi-metallic behavior. J. Mater. Chem. A 2019, 7, 10422-10430. [CrossRef]

38. Cardona, C.M.; Li, W.; Kaifer, A.E.; Stockdale, D.; Bazan, G.C. Electrochemical Considerations for Determining Absolute Frontier Orbital Energy Levels of Conjugated Polymers for Solar Cell Applications. Adv. Mater. 2011, 23, 2367-2371. [CrossRef]

39. Gayner, C.; Kar, K. Recent advances in thermoelectric materials. Prog. Mater. Sci. 2016, 83, $330-382$. [CrossRef]

40. Yamamoto, J.; Furukawa, Y. Electronic and vibrational spectra of positive polarons and bipolarons in regioregular poly(3-hexylthiophene) doped with ferric chloride. J. Phys. Chem. B 2015, 119, 4788-4794. [CrossRef] [PubMed]

41. Yang, H.; Ouyang, J.; Tang, A.; Xiao, Y.; Li, X.; Dong, X.; Yu, Y. Electrochemical synthesis and photocatalytic property of cuprous oxide nanoparticles. Mater. Res. Bull. 2006, 41, 1310-1318. [CrossRef]

42. Shi, K.; Zhang, F.; Di, C.; Yan, T.; Zou, Y.; Zhou, X.; Zhu, D.; Wang, J.; Pei, J. Toward High Performance n-Type Thermoelectric Materials by Rational Modification of BDPPV Backbones. J. Am. Chem. Soc. 2015, 137, 6979-6982. [CrossRef] [PubMed]

43. Scholes, D.; Yee, P.; Lindemuth, J.; Kang, H.; Onorato, J.; Ghosh, R.; Luscombe, C.; Spano, F.; Tolbert, S.; Schwartz, B. The Effects of Crystallinity on Charge Transport and the Structure of Sequentially Processed F4TCNQ-Doped Conjugated Polymer Films. Adv. Funct. Mater. 2017, 27, 1702654. [CrossRef]

44. Xing, K.; Fahlman, M.; Chen, X.; Inganas, O.; Salaneck, W. The electronic structure of poly(3,4-ethylenedioxythiophene): Studied by XPS and UPS. Synthetic Met. 1997, 89, 161-165. [CrossRef] 
45. Liang, Z.; Boland, M.; Butrouna, K.; Strachan, D.; Graham, K. Increased power factors of organic-inorganic nanocomposite thermoelectric materials and the role of energy filtering. J. Mater. Chem. A 2017, 5, 15891-15900. [CrossRef]

46. Mendez, H.; Heimel, G.; Opitz, A.; Sauer, K.; Barkowski, P.; Oehzelt, M.; Soeda, J.; Okamoto, T.; Takeya, J.; Arlin, J.; et al. Doping of organic semiconductors: Impact of dopant strength and electronic coupling. Angew. Chem. 2013, 52, 7751-7755. [CrossRef] [PubMed]

47. Patel, S.; Glaudell, A.; Peterson, K.; Thomas, E.; O’Hara, K.; Lim, E.; Chabinyc, M. Morphology controls the thermoelectric power factor of doped semiconducting polymer. Sci. Adv. 2017, 3, 1700434. [CrossRef]

(C) 2020 by the authors. Licensee MDPI, Basel, Switzerland. This article is an open access article distributed under the terms and conditions of the Creative Commons Attribution (CC BY) license (http://creativecommons.org/licenses/by/4.0/). 